\title{
Consulting the consultants: Avastin in the treatment of wet AMD
}

\author{
Ryian Mohamed (i] ${ }^{1} \cdot$ David C. Saunders $^{2} \cdot$ John P. Mathews ${ }^{3}$
}

Received: 10 October 2018 / Accepted: 12 October 2018 / Published online: 5 November 2018

(c) The Royal College of Ophthalmologists 2018

The recent high court judgment, published 21/09/18 [1], regarding Clinical Commissioning Group (CCG) policies on the use of Avastin (a non-licensed, lower cost-per-use alternative to Lucentis and Eylea), for wet AMD management, has opened a Pandora's box of unknowns for those now training or specializing in medical retina. Whilst legal history has been made, it is unclear how this ruling will impact ophthalmologists on the front line of service delivery. Worryingly, no data exist on what types of challenges are likely to arise, which leaves the professional body ill-equipped to foresee or meet the demands ahead. To address this, we conducted a survey questionnaire of consultant ophthalmologists across all sub-specialties $(n=13)$. A five-point scale from "strongly agree" to "strongly disagree" was used to identify key areas of concern regarding Avastin use in wet AMD, and an open comments box was incorporated for qualitative data capture (see Fig. 1).

We found that all participants either "agreed" (54\%) or "strongly agreed" (56\%) that drug licensing regulations were a challenge in offering wet AMD patients Avastin. Nobody "disagreed" or "strongly disagreed" that concerns over GMC action (23\% neutral, 31\% agree, and $46 \%$ strongly agree) and drug company marketing (38.5\% neutral, $23 \%$ agree, and $38.5 \%$ strongly agree) were also an issue. A greater range of responses was recorded for

Electronic supplementary material The online version of this article (https://doi.org/10.1038/s41433-018-0260-7) contains supplementary material, which is available to authorized users.

Ryian Mohamed

m0601207@gmail.com

1 ST1 Ophthalmology, Betsi Cadwaladr University Health Board, Abergele Hospital, Abergele, UK

2 Paediatric Ophthalmology, Betsi Cadwaladr University Health Board, Abergele Hospital, Abergele, UK

3 Medical Retina, Betsi Cadwaladr University Health Board, Abergele Hospital, Abergele, UK patient understanding and misinformation (8\% disagreed, $38.5 \%$ strongly agreed), Trust/Health board negotiation \& policy (15\% disagreed, $31 \%$ strongly agreed) and management support \& leadership (15\% disagreed, $31 \%$ strongly agreed). The greatest variation in responses was seen for ethical concerns (15\% strongly disagreed, $38.5 \%$ strongly agreed) and legal implications (8\% strongly disagreed, $38.5 \%$ strongly agreed).

Of the comments received a reoccurring theme was capacity, and whether current infrastructure can subsume the increased number of intravitreal injections (IVT) per patient required with Avastin compared with Lucentis [2]. Examples of feedback included: 'need to have a significant increase in clinic capacity' and 'capacity in IVT will worsen if Avastin introduced, needs to be addressed first'. Another theme was the lack of support from key players: 'This is a regulatory matter, to be solved by the regulators (MHRA) [Medicines and Healthcare products Regulatory Agency] and government. Doctors should not be being put in this position,' and 'The college and professional bodies have not been as strong a lobby as they should have been'. Interestingly, some unique change ideas were also suggested by the consultants surveyed. These ranged from: 'need to change SOP [Standard Operating Process] for nurse injectors' and 'public information exercise needed...RNIB [Royal National Institute for the Blind]/Macular Disease Society could help inform' to 'trusts should offer Avastin only as first line'.

What emerges is a unique snapshot of, as yet, unchartered territory. Multi-organizational co-operation from drug licensers, governing bodies, and health care leaders is required to achieve a national-level consensus that can provide clear clinical policy. As such, it remains to be seen if spinning high court ruling into clinical practice will be our new reality or our makebelieve. Until an outcome is clear, it is vital that prescribers are aware of current policy from licensors and governing bodies (see Table 1). 
The biggest challenge to offering patients Avastin in wet AMD is:

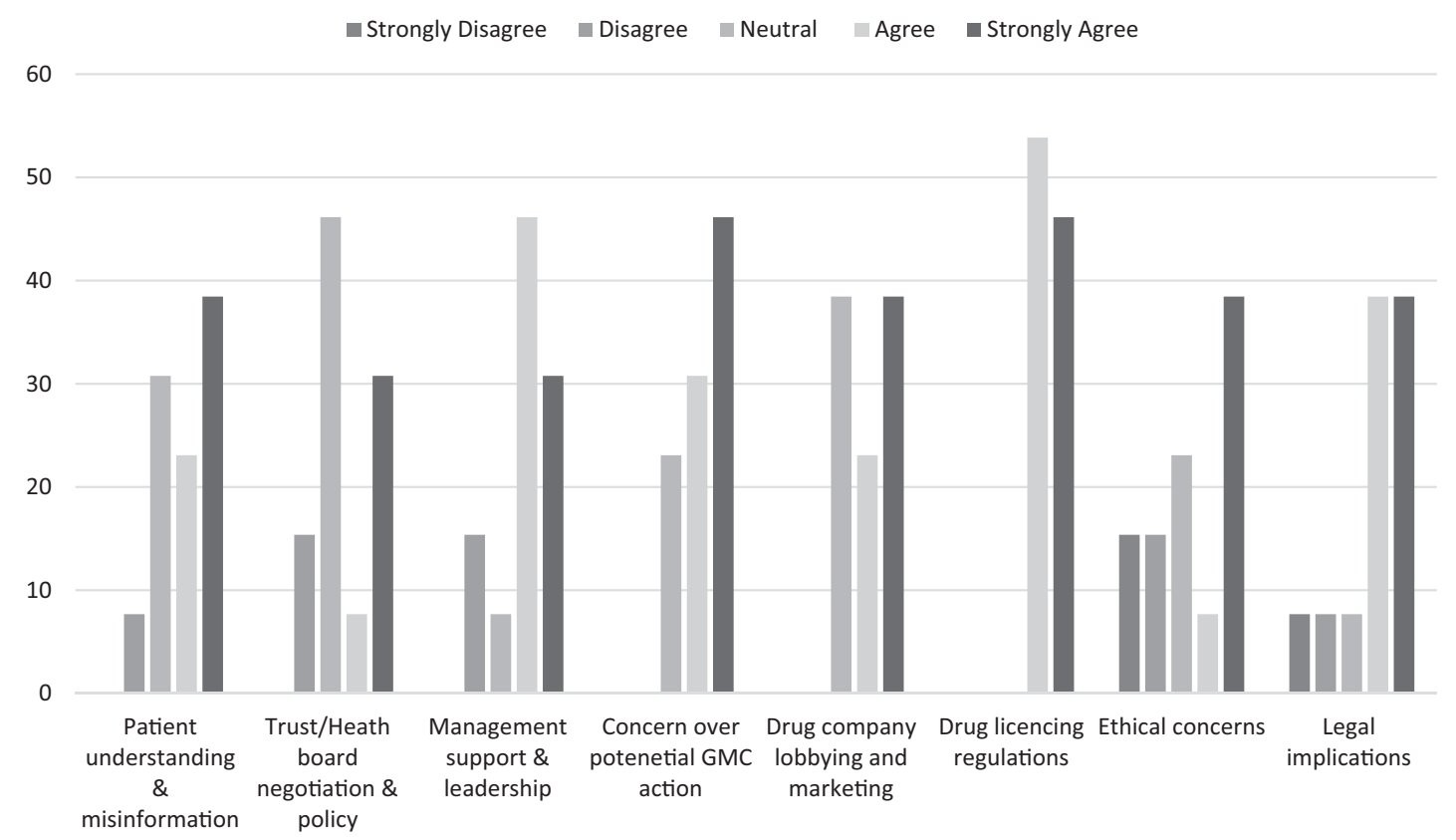

Fig. 1 Summary of ophthalmology consultant survey questionnaire results

Table 1 Statements to be aware of, regarding prescribing Avastin in wet AMD

\section{UK government [3]}

1.a "The responsibility that falls on healthcare professionals when prescribing an unlicensed medicine or a medicine off-label may be greater than when prescribing a licensed medicine within the terms of its licence"

1.b "Prescribers should pay particular attention to the risks associated with using unlicensed medicines or using a licensed medicine offlabel”

Medicines and Healthcare products Regulatory Agency (MHRA) [4]

2.a "If a UK licensed product can meet the clinical need, even off-label, it should be used instead of an unlicensed product"

2.b "The requirement for a "special need" relates to the special clinical needs of the individual patient, it does not include reasons of cost, convenience or operational needs"

Royal pharmaceutical Society (RPS) [5]

3.a "Specials, like all unlicensed medicines, should only be prescribed when there is no available licensed medicine which fully meets the patient's special clinical needs"

3.b Prescribers should "understand the patient's experience and make a shared decision"

3.c Prescribers should "take into account the safety, efficacy, quality and cost of the different Specials available to patients" and understand the "importance of reviewing and monitoring the patient regularly"

General Medical Council (GMC) [6, 7]

4.a "You should usually prescribe licensed medicines in accordance with the terms of their license. However, you may prescribe unlicensed medicines where, on the basis of an assessment of the individual patient, you conclude, for medical reasons, that it is necessary to do so to meet the specific needs of the patient"

4.b "You must ... be satisfied that there is sufficient evidence or experience of using the medicine to demonstrate its safety and efficacy"

4.c "Given the clinical support for using [bevacizumab], including from the Royal College of Ophthalmologists, we want to reassure doctors that this prescribing decision alone would not raise fitness to practice concerns, providing doctors are applying the broader principles of our guidance"

4.d "We cannot of course give specific clinical or legal advice. But we can say that where doctors are working in partnership with patients, following clinical guidance and making prescribing decisions in good faith on the basis of evidence and experience, the use of [bevacizumab] would not cause us any concerns" 
Table 1 (continued)

4.e "We are not here to protect doctors - their interests are protected by others. Our job is to protect the public."

Royal College of Ophthalmologists (RCOphth) [8]

5.a "Unlicensed or off license medicines should usually only be used when there is no suitable licensed medicine that will fulfill the patients need at the time the patient needs it"

5.b "A consultant must initiate all prescribing of new unlicensed medicines but afterwards other prescribers can continue its use,other prescribers may initiate unlicensed medicines if agreed by their individual trust"

5.c "Prescribers are professionally accountable for prescribing all medicines including unlicensed medicines"

5.d Prescribers must:

- "Be satisfied that there is a sufficient evidence base and/or experience of using the medicine to demonstrate its safety and efficacy"

- "Document the reasons for choosing the unlicensed medicine in the patient's records"

- "Ensure the patient is aware that the medicine is unlicensed and document in the patient records informed consent for the use of unlicensed medicines"

\section{Compliance with ethical standards}

Conflict of interest The authors declare that they have no conflict of interest.

\section{References}

1. High Court APPROVED judgement, Case No: CO/5288/2017. Available at: https://www.judiciary.uk/wp-content/uploads/2018/ 09/bayer-and-novartis-v-nhs-darlington-ccg-judgment. Accessed October 2018.

2. Berg K, Pedersen TR, Sandvik L, Bragadóttir R. Comparison of ranibizumab and bevacizumab for neovascular age-related macular degeneration according to LUCAS treat-and-extend protocol. Ophthalmology. 2015;122:146-52.

3. Off-label or unlicensed use of medicines: Prescribers' responsibilities. Available at: https://www.gov.uk/drug-safety-update/off-la bel-or-unlicensed-use-of-medicines-prescribers-responsibilities. Accessed October 2018.
4. The supply of unlicensed medicinal products ("specials"). Available at: https://www.gov.uk/government/uploads/system/uploads/a ttachment_data/file/373505/The_supply_of_unlicensed_medicinal_ products_specials_pdf. Accessed October 2018.

5. Prescribing Specials: Guidance for the prescribers of Specials. Available at: https://www.rpharms.com/Portals/0/RPS\%20document \%20library/Open\%20access/Support/toolkit/professional-standards--prescribing-specials.pdf. Accessed October 2018.

6. Prescribing unlicensed medicines. Available at: https://www.gmcuk.org/guidance/ethical_guidance/14327.asp. Accessed October 2018.

7. GMC responds to new NICE guidance on treating eye conditions. Available at: https://www.gmc-uk.org/news/31462.asp. Accessed October 2018.

8. Ophthalmic service guidance: Prescribing unlicensed medicines $-\mathrm{a}$ brief guide. Available at: https://www.rcophth.ac.uk/wp-content/ uploads/2018/03/Prescribing-Unlicensed-Medicines-A-brief-guide. pdf. Accessed October 2018. 